\title{
Time from Stereotactic Radiotherapy to Immunotherapy Is a Predictor for Outcome in Stage IV Non-Small Cell Lung Cancer
}

\author{
Rodney E. Wegner"*, Stephen Abel', Shaakir Hasan', Richard J. White', Gene Finley², Dulabh Monga' ${ }^{2}$, Athanasios \\ Colonias', Vivek Verma' \\ 'Allegheny Health Network Cancer Institute, Division of Radiation Oncology, USA \\ ${ }^{2}$ Allegheny Health Network Cancer Institute, Division of Medical Oncology, USA
}

Article Info

\section{Article Notes}

Received: April 10, 2019

Accepted: April 26, 2019

\section{Correspondence:}

Dr. Rodney E. Wegner, Allegheny Health Network Cancer Institute, Division of Radiation Oncology, $320 \mathrm{E}$. North Ave, Pittsburgh, PA 15212, USA; Phone No: 412-359-3400; Fax No: 412-359-3171; Email: Rodney.Wegner@ahn.org.

(c) 2019 Wegner RE. This article is distributed under the terms of the Creative Commons Attribution 4.0 International License.

\section{ABSTRACT}

Immunotherapy (IMT) has revolutionized the treatment of stage IV nonsmall cell lung cancer (NSCLC). However, optimal timing of IMT in relation to stereotactic radiosurgery (SRS) or stereotactic body radiotherapy (SBRT) is unknown. Utilizing the National Cancer Database, we examined trends in IMT use in metastatic NSCLC patients and the potential survival implications of IMT timing in relation to SBRT/SRS. We queried the NCDB for patients with Stage IV NSCLC diagnosed between 2004-2015. Patients receiving IMT and SBRT/SRS to any site were included. Multivariate logistic regression identified predictors of IMT use. Receiver operator characteristic curve analysis determined an a priori timeframe between SBRT and IMT predictive of optimal overall survival (OS). Univariate and multivariate analyses identified factors predictive of OS. Propensity-adjusted Cox proportional hazard ratios were used to mitigate indication bias. Of 13,862 eligible patients, 371 received IMT. The majority (75\%) received chemotherapy. IMT use was associated with improved median OS on univariate analysis (17 vs. 13 months, $p<0.0001)$. Adenocarcinoma histology, chemotherapy use, and recent treatment year were associated with IMT. On multivariate propensity-adjusted Cox regression, predictors for improved OS included: younger age, lower comorbidity score, lower grade, private insurance, IMT use, and female sex. Patients treated $\geq 21$ days ( $a$ priori threshold) after SBRT/SRS initiation had improved median OS (19 vs. 15 months, $p=0.0335$ ). In patients with Stage IV NSCLC, IMT use following SBRT/ SRS has increased. OS improved when IMT was given $\geq 3$ weeks after initiating SBRT/SRS; suggesting a potential optimal time-frame between RT and IMT.

\section{Background}

Lung cancer remains the leading cause of cancer mortality worldwide, with non-small cell lung cancer (NSCLC) accounting for the vast majority of cases ${ }^{1}$. Despite advances in diagnostic imaging and population based screening recommendations, many NSCLC patients still present with advanced disease ${ }^{2}$. In patients with stage IV disease, systemic therapy, in the form of chemotherapy, has been the mainstay of treatment. While often efficacious, chemotherapy affects normal and malignant tissue rather indiscriminately, contributing to normal tissue toxicity. More recently, the development of targeted therapy for gene mutations in NSCLC has helped individualize treatment for this patient population ${ }^{3}$. Likewise, the role for immunotherapy (IMT) in advanced NSCLC continues to expand, and is quickly becoming the standard of care ${ }^{4}$ 5. Similarly, radiation therapy (RT) is playing a larger role in the metastatic setting. Historically limited to palliation, RT has been increasingly utilized in the treatment of oligometastatic disease, as emerging data suggests improved outcomes ${ }^{6,7}$. 
Radiation therapy and IMT may synergize, a factor that is being increasingly appreciated as an oncologic tool, and is the basis for multiple ongoing clinical trials ${ }^{8}$. Mechanistically, this is associated with RT-mediated antigen release, recognition by antigen-presenting cells, presentation of neoplastic antigens to $\mathrm{T}$ lymphocytes, priming and proliferation thereof, and lymphocyticmediated tumoral destruction'. Because RT and the tumor stroma release soluble factors that result in a relative immunosuppressive milieu, this process occurs to a relatively low degree in most cases ${ }^{10}$. However, inhibition of some immunosuppressive signals by means of drugs targeting these so-called "immune checkpoints" may be a means to better galvanize the de novo immune system.

Nevertheless, the optimal timing of RT and IMT remains unresolved. Theoretically, a specified duration between RT-mediated antigen release and delivery of immunoactive compounds should be advantageous in order to allow time for immune recognition, which has been performed in multiple clinical trials ${ }^{11}$. However, meta-analyses have found that concurrent therapy may be most optimal ${ }^{12,13}$. Thus, we sought to use the National Cancer Database (NCDB) to examine patterns of use and timing of IMT in stage IV NSCLC, specifically in relation to those patients receiving ablative doses of radiation (which may better induce systemic immune-mediated responses) using stereotactic radiosurgery (SRS) or stereotactic body radiotherapy (SBRT).

\section{Methods}

The methodology underscoring analyses of the NCDB have been previously reported ${ }^{14,15}$. This retrospective review consisted of de-identified data from the NCDB; therefore an IRB waiver was permitted. Overseen by the American Cancer Society and American College of Surgeons, the NCDB encompasses an estimated $70 \%$ of annual cancer cases in the United States. The American College of Surgeons and the Commission on Cancer have not verified and are not responsible for the analytic or statistical methodology employed, or the conclusions drawn from these data by the investigator.

Patients with documented clinical stage IV NSCLC who received radiation to any site using either SRS or SBRT (per NCDB coding). Figure 1 is a CONSORT diagram outlining the cohort selection criteria. We excluded patients not receiving radiation or having unknown/inadequate (i.e. $<3$ months) follow up to account for immortal time bias.

Race was categorized as Caucasian, African American, or other. The Charlson/Deyo comorbidity index quantified the degree of comorbidities ${ }^{16}$. Socioeconomic data in the patients' residence census tract were divided into quartiles based upon the percentage of persons with less than a high school education and median household income. Facility

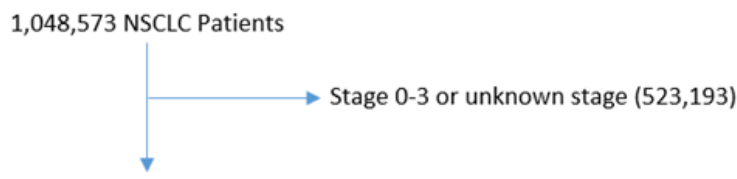

525,380 Patients

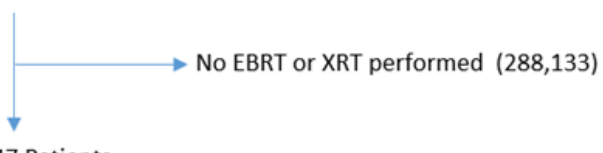

237,247 Patients

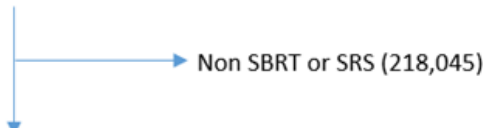

19,202 Patients

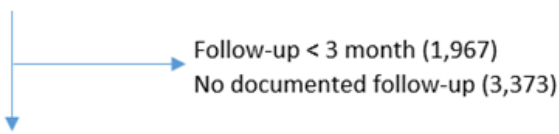

13,862 patients with stage IV NSCLC
treated with SRS, SBRT or ablative

XRT and at least 3 months follow up

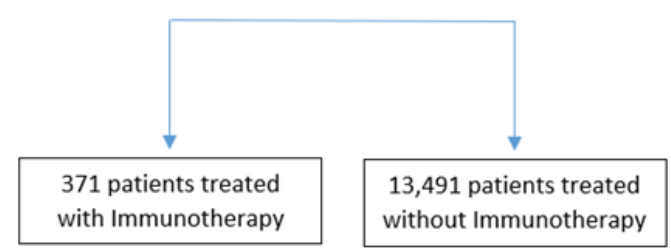

Figure 1: CONSORT diagram.

type was grouped according to the Commission on Cancer accreditation category. Locations were described based on data provided by the US Department of Agriculture Economic Research Service. Insurance status is documented in the NCDB as it appears on the admission page.

Data were analyzed using Medcalc Version 18 (Ostend, Belgium). Summary statistics are presented for discrete variables. Chi-square tests compared sociodemographic, treatment, and tumor characteristics between the treatment groups. Overall survival is recorded in the NCDB in months from time of diagnosis to death, or censored at last contact. Kaplan-Meier curves were used to calculate cumulative probability of survival ${ }^{17}$. Log-rank statistics were used to test for a statistically significant difference in the cumulative proportions across groups. A multivariate survival analysis was conducted using a Cox proportional hazards model ${ }^{18}$. Factors significant on univariate analysis were entered using a stepwise elimination process. Adjusted hazard ratios and 95\% confidence intervals are reported, using an alpha level of 0.05 to indicate statistical significance. A receiver operator characteristics (ROC) curve analysis was performed to identify the optimal time from SBRT/SRS to IMT that best correlated with outcome.

To account for indication biases associated with lack of randomization, propensity score-matching was 
applied to the multivariate survival analysis ${ }^{19}$. Multivariate logistic regression was used to calculate a propensity score indicative of conditional probability of receiving IMT. The propensity model included observable variables associated with treatment selection on multivariate logistic regression. A Cox proportional hazards model was then constructed allowing for incorporation of the propensity score, but also excluding factors included in the propensity score calculation to avoid overcorrection. The assumption of balance was further validated by stratifying the data into propensity score-based quintiles, and confirming that the difference in propensity score mean per quintile was less than 0.10 .

\section{Results}

We identified 13,862 patients meeting the above eligibility criteria in the NCDB between 2004 and 2014 (Table 1).

Table 1. Patient Demographics and Clinical Characteristics at Baseline $(n=13,862)$.

\begin{tabular}{|c|c|}
\hline Characteristics & No. (\%) \\
\hline \multicolumn{2}{|l|}{ Sex } \\
\hline Male & $6,746(49)$ \\
\hline Female & $7,116(51)$ \\
\hline \multicolumn{2}{|l|}{ Race } \\
\hline White & $11,748(85)$ \\
\hline African American & $1,497(11)$ \\
\hline Other & $617(4)$ \\
\hline \multicolumn{2}{|l|}{ Comorbidity Score } \\
\hline 0 & $9,766(71)$ \\
\hline 1 & $2,957(21)$ \\
\hline$\geq 2$ & $1,139(8)$ \\
\hline \multicolumn{2}{|l|}{ Insurance } \\
\hline Not Insured & $374(3)$ \\
\hline Private Payer & $5,507(40)$ \\
\hline Government & $7,785(56)$ \\
\hline Unrecorded & $196(1)$ \\
\hline \multicolumn{2}{|l|}{ Education \% } \\
\hline$\geq 29$ & $2,108(15)$ \\
\hline 20 to 28.9 & $3,534(26)$ \\
\hline 14 to 19.9 & $4,684(34)$ \\
\hline$<14$ & $3,338(25)$ \\
\hline \multicolumn{2}{|l|}{ Treatment Facility type } \\
\hline Community cancer program & $679(5)$ \\
\hline Comprehensive community cancer program & $4,718(34)$ \\
\hline Academic/research program & $8,308(61)$ \\
\hline \multicolumn{2}{|l|}{ Treatment facility location } \\
\hline Metro & $11,222(80)$ \\
\hline Urban & $1,883(14)$ \\
\hline Rural & $227(2)$ \\
\hline Unrecorded & $530(4)$ \\
\hline Income, US dollars & \\
\hline
\end{tabular}

\begin{tabular}{|l|c|}
\hline$<30,000$ & $2,426(18)$ \\
30,000 to 35,000 & $3,072(22)$ \\
35,000 to 45,999 & $3,651(27)$ \\
\hline$>46,000$ & $4,511(33)$ \\
\hline Distance to treatment facility, miles & \\
\hline $\begin{array}{l}\leq 12 \text { miles } \\
>12 \text { miles }\end{array}$ & $6,971(50)$ \\
\hline Age distribution, years & $6,891(50)$ \\
\hline$\leq 64$ & $6,845(49)$ \\
\hline$>64$ & $7,017(51)$ \\
\hline Year of Diagnosis & \\
\hline $2004-06$ & $1,534(11)$ \\
\hline $2007-09$ & $2,778(20)$ \\
\hline $2010-12$ & $4,832(35)$ \\
\hline $2013-15$ & $4,718(34)$ \\
\hline Histology & \\
\hline Squamous Cell Carcinoma & $1,806(13)$ \\
\hline Adenocarcinoma & $8,427(60)$ \\
\hline Large Cell Neuroendocrine Carcinoma & $377(3)$ \\
\hline NSCLC, NOS & $3,252(24)$ \\
\hline Chemotherapy & \\
\hline No & $3,513(25)$ \\
\hline Yes & $10,349(75)$ \\
\hline Grade & $303(5)$ \\
\hline Well Differentiated & $1,449(25)$ \\
\hline Moderately Differentiated & \\
\hline Poorly Differentiated & $(70)$ \\
\hline
\end{tabular}

Of that group, 371 (2.6\%) received IMT. The use of IMT in this population increased over time, from $2 \%$ in 2004 to $9 \%$ in 2014 . The median dose of radiation was $24 \mathrm{~Gy}$ (interquartile range: 20-60 Gy) in 1 fraction (interquartile range: $1-5)$. The median time to SRS/SBRT was 35 days from diagnosis (interquartile range: 20-57 days). The sites of treatment included brain (80\%), lung (14\%), and other $(6 \%)$. The median time to IMT was 55 days (interquartile range: $38-86$ days). The majority of patients (75\%) received chemotherapy at a median time of 43 days from diagnosis (interquartile range: 28-65 days). Administration of IMT was more frequent in patients who received chemotherapy, had adenocarcinoma histology, and were treated more recently (Table 2).

The median follow-up was 12.8 months (range, 3-150 months). Kaplan-Meier analysis showed improved median overall survival with IMT (17 months vs. 13 months, $\mathrm{p}<0.0001$, Figure 2). On multivariate unadjusted Cox regression, significant predictors for improved overall survival were younger age, lower comorbidity score, lower grade, private insurance, chemotherapy use, adenocarcinoma, more recent year of treatment, and female sex (Table 3).

Given that chemotherapy is the most fundamental aspect of management for stage IV NSCLC, and to address 
Table 2. Multivariable logistic regression to generate odds ratios for receiving immunotherapy in addition to SBRT/SRS.

\begin{tabular}{|c|c|c|}
\hline Characteristic & Endpoint: Immunotherapy & $\mathbf{p}$ \\
\hline & OR(95\% Cl) & \\
\hline \multicolumn{3}{|l|}{ Age } \\
\hline Age $\leq 64$ & Reference & \\
\hline Age $>64$ & 0.8767 (0.6660 to 1.1541$)$ & 0.3483 \\
\hline \multicolumn{3}{|l|}{ Chemotherapy } \\
\hline No & Reference & \\
\hline Yes & 4.3146 (2.8266 to 6.5859 ) & $<0.0001$ \\
\hline \multicolumn{3}{|l|}{ Comorbidity Score } \\
\hline 0 & Reference & \\
\hline 1 & 0.9969 (0.7655 to 1.2982$)$ & 0.9817 \\
\hline$\geq 2$ & 0.7812 (0.4960 to 1.2302$)$ & 0.2865 \\
\hline \multicolumn{3}{|l|}{ Distance } \\
\hline $\begin{array}{l}\text { Distance } \leq 12 \\
\text { miles }\end{array}$ & Reference & \\
\hline $\begin{array}{l}\text { Distance }>12 \\
\text { miles }\end{array}$ & 1.0702 (0.8476 to 1.3511$)$ & 0.5686 \\
\hline \multicolumn{3}{|l|}{ Facility Type } \\
\hline Community & Reference & \\
\hline $\begin{array}{c}\text { Comprehensive } \\
\text { Community Program }\end{array}$ & $0.7780(0.4834$ to 1.2520$)$ & 0.3011 \\
\hline $\begin{array}{l}\text { Academic/Re- } \\
\text { search Program }\end{array}$ & 0.8351 (0.5271 to 1.3232$)$ & 0.4429 \\
\hline \multicolumn{3}{|l|}{ Grade } \\
\hline $\begin{array}{l}\text { Well differenti- } \\
\text { ated }\end{array}$ & Reference & \\
\hline $\begin{array}{l}\text { Moderately Dif- } \\
\text { ferentiated }\end{array}$ & 0.5726 (0.2775 to 1.1813$)$ & 0.1313 \\
\hline $\begin{array}{l}\text { Poorly Differen- } \\
\text { tiated }\end{array}$ & 0.6013 (0.3065 to 1.1799$)$ & 0.1391 \\
\hline \multicolumn{3}{|l|}{ Histology } \\
\hline $\begin{array}{l}\text { Squamous Cell } \\
\text { Carcinoma }\end{array}$ & Reference & \\
\hline Adenocarcinoma & 4.3730 (2.4284 to 7.8747$)$ & $<0.0001$ \\
\hline $\begin{array}{l}\quad \text { Large Cell Neuro- } \\
\text { endocrine Carci- } \\
\text { noma }\end{array}$ & 2.4465 (0.8958 to 6.6813$)$ & 0.809 \\
\hline NSCLC NOS & 3.2057 (1.6971 to 6.0553$)$ & 0.0003 \\
\hline \multicolumn{3}{|l|}{$\begin{array}{l}\text { High School Educa- } \\
\text { tion, } \%\end{array}$} \\
\hline$\geq 29$ & Reference & \\
\hline 20 to 28.9 & 1.0955 (0.7543 to 1.5912$)$ & 0.6318 \\
\hline 14 to 19.9 & 1.0641 (0.7159 to 1.5816$)$ & 0.7587 \\
\hline$<14$ & $1.1228(0.7072$ to 1.7829$)$ & 0.6233 \\
\hline \multicolumn{3}{|l|}{ Income, USD } \\
\hline 30,000 & Reference & \\
\hline $30,000-35,000$ & 1.0848 (0.7397 to 1.5907$)$ & 0.6770 \\
\hline $35,000-45,999$ & 1.0421 (0.6983 to 1.5552$)$ & 0.8401 \\
\hline$>46,000$ & 0.9678 (0.6153 to 1.5221$)$ & 0.8872 \\
\hline \multicolumn{3}{|l|}{ Insurance } \\
\hline None & Reference & \\
\hline Private & 1.1192 (0.5882 to 2.1293$)$ & 0.7316 \\
\hline Government & 1.0242 (0.5291 to 1.9826$)$ & 0.9435 \\
\hline Location & & \\
\hline
\end{tabular}

\begin{tabular}{|l|l|l|}
\hline Metropolitan & Reference & \\
\hline Urban & $0.8188(0.5660$ to 1.1845$)$ & 0.2885 \\
\hline Rural & $1.1081(0.4907$ to 2.5022$)$ & 0.8050 \\
\hline Race & & \\
\hline Caucasian & Reference & \\
\hline African American & $0.8096(0.5507$ to 1.1903$)$ & 0.2828 \\
\hline Other & $1.1916(0.7687$ to 1.8471$)$ & 0.4332 \\
\hline Gender & & \\
\hline Male & Reference & \\
\hline Female & $1.1013(0.8874$ to 1.3668$)$ & 0.3812 \\
\hline Year & & \\
\hline $2004-06$ & Reference & \\
\hline $2007-09$ & $0.0757(0.0172$ to 0.3337$)$ & 0.0007 \\
\hline $2010-12$ & $0.3466(0.1698$ to 0.7075$)$ & 0.0036 \\
\hline $2013-14$ & $7.5731(4.3914$ to 13.0599$)$ & $<0.0001$ \\
\hline
\end{tabular}

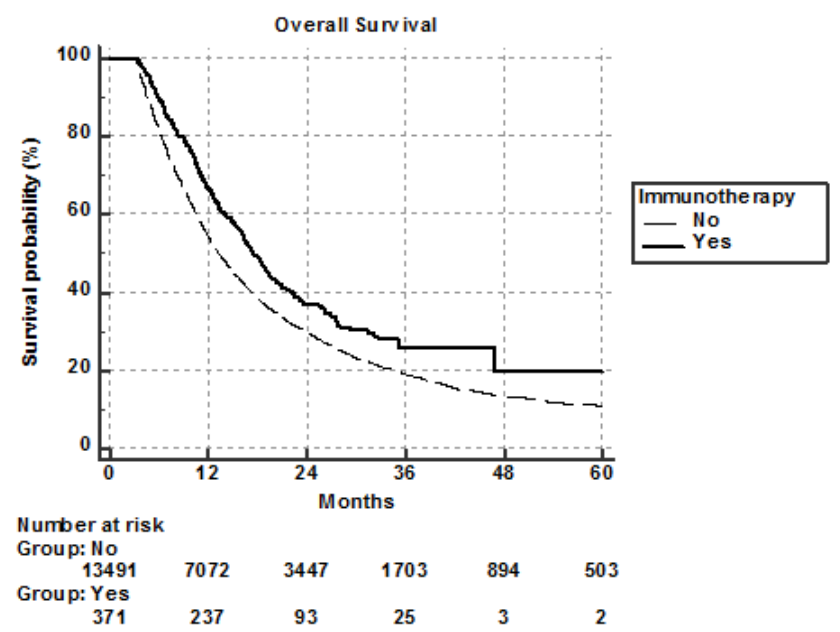

Figure 2: Survival was improved with the use of immunotherapy, median survival of 17 months compared to 13 months, $p<0.0001$.

Table 3. Multivariable Cox regression for predictors of Overall Survival with and without propensity adjustment.

\begin{tabular}{|c|c|c|}
\hline Characteristic & HR $(95 \% \mathrm{Cl})$ & $\mathbf{p}$ \\
\hline & Model without Propensity Score & \\
\hline \multicolumn{3}{|l|}{ Age } \\
\hline$\leq 64$ & Reference & \\
\hline$>64$ & 1.1168 (1.0650 to 1.1712$)$ & $<0.0001$ \\
\hline \multicolumn{3}{|l|}{ Comorbidity Score } \\
\hline 0 & Reference & \\
\hline 1 & 1.0601 (1.0125 to 1.1099$)$ & 0.0128 \\
\hline$\geq 2$ & 1.1209 (1.0471 to 1.1999$)$ & 0.0010 \\
\hline \multicolumn{3}{|l|}{ Distance } \\
\hline$\leq 12$ miles & Reference & \\
\hline$>12$ miles & 0.9316 (0.8940 to 0.9707$)$ & 0.0007 \\
\hline \multicolumn{3}{|l|}{ Grade } \\
\hline Well Differentiated & Reference & \\
\hline $\begin{array}{l}\text { Moderately Differ- } \\
\text { entiated }\end{array}$ & 1.1215 (0.9749 to 1.2902$)$ & 0.1088 \\
\hline $\begin{array}{l}\text { Poorly Differenti- } \\
\text { ated }\end{array}$ & 1.3605 (1.1916 to 1.5533$)$ & $<0.0001$ \\
\hline
\end{tabular}




\begin{tabular}{|c|c|c|}
\hline \multicolumn{3}{|l|}{ Insurance } \\
\hline None & Reference & \\
\hline Private & 0.8101 (0.7207 to 0.9105$)$ & 0.0004 \\
\hline Government & 0.8800 (0.7808 to 0.9917$)$ & 0.0360 \\
\hline \multicolumn{3}{|l|}{ Chemotherapy } \\
\hline No & Reference & \\
\hline Yes & 0.8915 (0.8537 to 0.9309$)$ & $<0.0001$ \\
\hline \multicolumn{3}{|l|}{ Race } \\
\hline Caucasian & Reference & \\
\hline African American & 1.0545 (0.9892 to 1.1241$)$ & 0.1036 \\
\hline Other & $0.8068(0.7333$ to 0.8876$)$ & $<0.0001$ \\
\hline \multicolumn{3}{|l|}{ Gender } \\
\hline Male & Reference & \\
\hline Female & 0.8444 (0.8135 to 0.8763$)$ & $<0.0001$ \\
\hline \multicolumn{3}{|l|}{ Histology } \\
\hline $\begin{array}{l}\text { Squamous Cell } \\
\text { Carcinoma }\end{array}$ & Reference & \\
\hline Adenocarcinoma & $0.7126(0.6736$ to 0.7540$)$ & $<0.0001$ \\
\hline $\begin{array}{l}\text { Large Cell Neuro- } \\
\text { endocrine Carcinoma }\end{array}$ & 0.9977 (0.8860 to 1.1236$)$ & 0.9703 \\
\hline NSCLC, NOS & 0.8823 (0.8285 to 0.9396$)$ & 0.0001 \\
\hline \multicolumn{3}{|l|}{ Year of treatment } \\
\hline 2004-2006 & Reference & \\
\hline $2007-2009$ & 0.8667 (0.8123 to 0.9248$)$ & $<0.0001$ \\
\hline 2010-2012 & 0.8170 (0.7684 to 0.8687$)$ & $<0.0001$ \\
\hline $2013-2015$ & 0.7349 (0.6888 to 0.7840$)$ & $<0.0001$ \\
\hline \multirow[t]{2}{*}{ Characteristic } & HR $(95 \% \mathrm{Cl})$ & $\mathbf{p}$ \\
\hline & Model with Propensity Score & \\
\hline \multicolumn{3}{|c|}{ 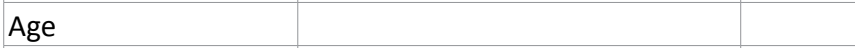 } \\
\hline$\leq 64$ & Reference & \\
\hline$>64$ & 1.1324 (1.0655-1.1894) & $<0.0001$ \\
\hline \multicolumn{3}{|l|}{ Comorbidity Score } \\
\hline 0 & Reference & \\
\hline 1 & $1.0826(1.0261-1.1 .1423)$ & 0.0037 \\
\hline$\geq 2$ & $1.1485(1.0559-1.2492)$ & 0.0012 \\
\hline \multicolumn{3}{|l|}{ Distance } \\
\hline$\leq 12$ miles & Reference & \\
\hline$>12$ miles & $0.9286(0.8853-0.9742)$ & 0.0024 \\
\hline \multicolumn{3}{|l|}{ Grade } \\
\hline Well differentiated & Reference & \\
\hline $\begin{array}{l}\text { Moderately differ- } \\
\text { entiated }\end{array}$ & $1.0900(0.9167-1.2962)$ & 0.3294 \\
\hline $\begin{array}{l}\text { Poorly Differenti- } \\
\text { ated }\end{array}$ & $1.4332(1.2160-1.6891)$ & $<0.0001$ \\
\hline \multicolumn{3}{|l|}{ Insurance } \\
\hline None & Reference & \\
\hline Private & $0.8240(0.7331-0.9261)$ & 0.0012 \\
\hline Government & $0.8999(0.7985-1.0140)$ & 0.0834 \\
\hline \multicolumn{3}{|l|}{$\begin{array}{l}\text { High school educa- } \\
\text { tion, \% }\end{array}$} \\
\hline$>29$ & Reference & \\
\hline 20 to 28.9 & $1.0860(1.0069-1.1714)$ & 0.0325 \\
\hline 14 to 19.9 & $1.0628(0.9798-1.1528)$ & 0.1421 \\
\hline$<14$ & $1.0216(0.9297-1.1225)$ & 0.6566 \\
\hline Immunotherapy & & \\
\hline
\end{tabular}

\begin{tabular}{|l|l|c|}
\hline \multicolumn{1}{|c|}{ No } & Reference & \\
\hline Yes & $0.8269(0.7245-0.9438)$ & 0.0048 \\
\hline Facility Type & Reference & \\
\hline $\begin{array}{c}\text { Community } \\
\text { Comprehensive } \\
\text { Community Program } \\
\begin{array}{c}\text { Academic/Re- } \\
\text { search Program }\end{array}\end{array}$ & $0.9274(0.8381-1.0262)$ & 0.1445 \\
\hline Race & $0.9011(0.8158-0.9952)$ & 0.0399 \\
\hline Caucasian & Reference & \\
\hline African American & $0.9957(0.9245-1.0723)$ & 0.9087 \\
\hline Other & $0.8177(0.7370-0.9072)$ & $<0.0001$ \\
\hline Sex & Reference & \\
\hline Male & $0.8080(0.7739-0.8435)$ & $<0.0001$ \\
\hline Female & & \\
\hline
\end{tabular}

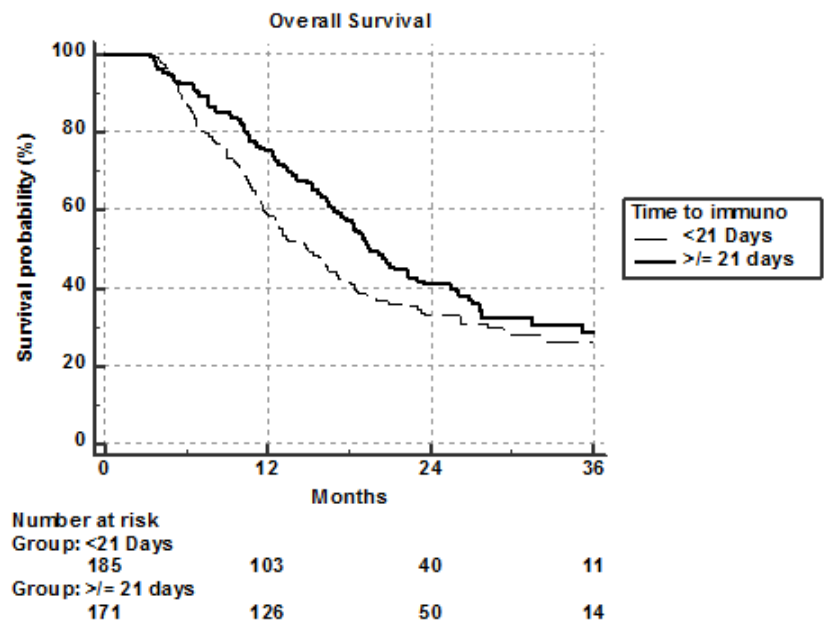

Figure 3: Survival in patients receiving immunotherapy by time from SBRT. Survival was improved with time of at least 21 days prior to immunotherapy, median survival of 19 months vs. 14 months, $p=0.03$.

indication biases owing to many (poorer prognostic) patients not having received chemotherapy, we repeated multivariate Cox regression on a propensity-matched population who received chemotherapy. In doing so, significant predictors for improved overall survival were younger age, lower comorbidity score, lower grade, private insurance, use of IMT, treatment at an academic facility, and female sex (Table 4).

As described in the methods, a ROC curve analysis was conducted to identify an optimal timeframe between IMT and SBRT/SRS. Results of that analysis indicated an optimal timeframe of 14-21 days. Kaplan-Meier analysis was performed based upon whether patients had IMT at least 21 days after start of SBRT/SRS (versus lack thereof). Overall survival was improved in those receiving IMT at least 21 days after SBRT/SRS compared to those receiving IMT less than 21 days after SBRT/SRS (median 19 vs. 14 months, $p=0.03$, Figure 3 ). 
Table 4. Multivariable Cox regression for predictors of overall survival with propensity score in patients that received chemo.

\begin{tabular}{|c|c|c|}
\hline \multirow[t]{2}{*}{ Significant Characteristic } & HR (95\% Cl) & $\mathbf{P}$ \\
\hline & Cox model with propensity score & \\
\hline \multicolumn{3}{|l|}{ Age } \\
\hline$\leq 64$ & Reference & \\
\hline$>64$ & $1.1324(1.0655-1.1894)$ & $<0.0001$ \\
\hline \multicolumn{3}{|l|}{ Comorbidity Score } \\
\hline 0 & Reference & \\
\hline 1 & $1.0826(1.0261-1.1 .1423)$ & 0.0037 \\
\hline$\geq 2$ & $1.1485(1.0559-1.2492)$ & 0.0012 \\
\hline \multicolumn{3}{|l|}{ Distance } \\
\hline$\leq 12$ miles & Reference & \\
\hline$>12$ miles & $0.9286(0.8853-0.9742)$ & 0.0024 \\
\hline \multicolumn{3}{|l|}{ Grade } \\
\hline Well differentiated & Reference & \\
\hline Moderately differentiated & $1.0900(0.9167-1.2962)$ & 0.3294 \\
\hline Poorly Differentiated & $1.4332(1.2160-1.6891)$ & $<0.0001$ \\
\hline \multicolumn{3}{|l|}{ Insurance } \\
\hline None & Reference & \\
\hline Private & $0.8240(0.7331-0.9261)$ & 0.0012 \\
\hline Government & $0.8999(0.7985-1.0140)$ & 0.0834 \\
\hline \multicolumn{3}{|l|}{ High school education, \% } \\
\hline$>29$ & Reference & \\
\hline 20 to 28.9 & 1.0860 (1.0069-1.1714) & 0.0325 \\
\hline 14 to 19.9 & $1.0628(0.9798-1.1528)$ & 0.1421 \\
\hline$<14$ & $1.0216(0.9297-1.1225)$ & 0.6566 \\
\hline \multicolumn{3}{|l|}{ Immunotherapy } \\
\hline No & Reference & \\
\hline Yes & $0.8269(0.7245-0.9438)$ & 0.0048 \\
\hline \multicolumn{3}{|l|}{ Facility Type } \\
\hline Community & Reference & \\
\hline $\begin{array}{l}\text { Comprehensive Commu- } \\
\text { nity Program }\end{array}$ & $0.9274(0.8381-1.0262)$ & 0.1445 \\
\hline $\begin{array}{l}\text { Academic/Research } \\
\text { Program }\end{array}$ & $0.9011(0.8158-0.9952)$ & 0.0399 \\
\hline \multicolumn{3}{|l|}{ Race } \\
\hline Caucasian & Reference & \\
\hline African American & $0.9957(0.9245-1.0723)$ & 0.9087 \\
\hline Other & $0.8177(0.7370-0.9072)$ & $<0.0001$ \\
\hline \multicolumn{3}{|l|}{ Sex } \\
\hline Male & Reference & \\
\hline Female & $0.8080(0.7739-0.8435)$ & $<0.0001$ \\
\hline
\end{tabular}

\section{Discussion}

Despite the mounting evidence regarding the facilitative relationship between RT and IMT, optimal timing of both modalities remains limited to theoretical discussions rather than having an established evidence base. To address this knowledge gap, we performed this analysis of a large, contemporary national database. The results demonstrated that there may be an optimal timeframe between RT and IMT administration (2-3 weeks), supporting theoretical evidence that time may be required for immune recognition following RT-mediated antigen release and prior to immunoproliferation. These results also have implications for randomized trials addressing this issue in metastatic NSCLC (NCT03223155).

Despite two recent meta-analyses stating that concurrent therapy may be superior to sequential therapy ${ }^{12,13}$, there are two prospective trials that support our findings of sequential RT followed by IMT. First, a secondary analysis of the KEYNOTE-001 trial demonstrated that prior RT enhanced the efficacy (progression-free and overall survival) of pembrolizumab in advanced NSCLC cases, as compared to the lack of prior $\mathrm{RT}^{20}$. Additionally, an exploratory analysis of the PACIFIC trial illustrated that commencing durvalumab within a 14-day threshold of completing chemoradiotherapy was associated with proportionally higher progression-free survival (PFS) benefits as compared to $>14$ days. This cutoff, albeit based on a post hoc analysis, is similar to the 2-3 weeks we found herein.

The main drawback regarding concurrent RT and IMT is the theoretical increase in toxicity risks. For this reason, some randomized trials mandated completion of thoracic RT well in advance of IMT administration ${ }^{21}$, and others excluded patients who underwent supra-palliative doses within several months of IMT ${ }^{22}$. However, a few recent publications have concluded that combined - and concurrent - immunoradiotherapy does not confer an overtly increased risk of adverse events ${ }^{23-25}$.

We chose to include only ablative RT in this analysis for multiple reasons. First, it has been observed that ablative dosing in many neoplasms offers tumor control benefits over conventional fractionation ${ }^{26}$, but the cause remains relatively unknown. As a result, some have posited that systemic effects of local, ablative-dosed RT may be much higher than conventional fractionation ${ }^{27,28}$. Additionally, this notion has also been convincingly shown in preclinical data, which even suggest that an ablative dose-perfraction threshold may be important to balance the fine line between RT-induced immune "encouragement" and "discouragement".

We also opted to perform a specific propensity-matched analysis in patients who received chemotherapy. This was primarily to remove patients too "frail" to receive chemotherapy; these types of patients are almost always excluded from IMT trials and likely do not benefit from IMT $^{29,30}$. These notions are supported by the present study, because IMT was not associated with survival in the overall non-adjusted population, but only so in the propensitymatched chemotherapy population. Although delivery of chemotherapy and IMT may incur toxicities, this remains a management approach for these patients, and was an arm of the KEYNOTE-189 investigation ${ }^{5}$. 
Classically, patients with stage IV NSCLC were considered incurable and the focus of treatment was on prolonged survival and quality of life. There are instances, however, where despite being metastatic, the disease is truly limited, contemporarily referred to as oligometastasis ${ }^{31}$. According to the concept, first described by Hellman and colleagues in 1995, the goal of treatment in such patients is to provide aggressive local therapy potentially rendering them disease-free for a protracted interval. Criteria for defining oligometastatic disease varies by institution, protocol, and publication, keeping in mind additional factors such as total disease volume, genetics, histology, and location may also impact the outcome ${ }^{32}$. A few recent trials have presented exciting data showing improved outcomes utilizing SRS and SBRT in these patients. The first trial, SABR-COMET, was presented at ASTRO 2018 and enrolled 99 patients with various malignancies with up to 5 sites of metastatic disease ${ }^{6}$. Patients either received standard of care or standard of care plus SBRT/SRS to sites of metastasis. The median overall survival was 41 months in the SBRT arm compared to 28 months in the standard of care arm. Similarly, progression free survival was improved from 6 months to 12 months in favor of SBRT. There was an increase in grade 2 or higher toxicity in the SBRT arm $29 \%$ compared to $9 \%$. Another trial, presented at the same meeting, enrolled 49 patients all with metastatic NSCLC that had not progressed after initial systemic therapy and had 3 or less sites of metastasis ${ }^{7}$. Consolidative therapy in this study was either surgery or SRS/SBRT, and compared to ongoing standard maintenance therapy. With a median follow up of 38 months the median overall survival was 41 months compared to 17 months in favor of local consolidative therapy ( $\mathrm{p}=0.017)$. Progression free survival was likewise improved from 4.4 months to 14.2 months ( $p=0.014)$. Of note, neither of these trials examined incorporation of novel therapeutic agents such as IMT or targeted therapy.

To that end there are several ongoing trials looking at ways to incorporate targeted therapy and IMT in the oligometastatic setting ${ }^{33}$. The rationale behind combining IMT and radiation is that there is evidence that radiation promotes antigen exposure, making IMT more effective ${ }^{34}$ ${ }^{35}$. Many of these ongoing trials incorporate ablative doses of radiation through SRS or SBRT. There is some preclinical data showing that using higher dose per fraction results in higher tumor immunogenicity ${ }^{36}$. Along those lines, a recent NCDB analysis on brain metastases form melanoma treated with radiation showed improved outcomes (overall survival) with SRS and IMT ${ }^{37}$. The results of the present study certainly corroborate the findings discussed above. As expected, we showed a significant increase in IMT over time from $2 \%$ to $9 \%$. There was a survival benefit with the use of IMT in those patients receiving chemotherapy, consistent with the results of recent randomized trials. In addition, the time point of 21 days following start of SBRT (or what would be 1-2 weeks following completion of SRS/ SBRT) correlating with improved survival makes sense in that it allows time for the increase in immunogenicity after ablative doses of radiation.

There are several limitations to the data presented here, mainly relating to the retrospective nature of the study and inherent selection bias. In addition, the NCDB does not carry information regarding specific IMT/chemotherapy agents, doses, or duration. In addition, using the NCDB it is impossible to tell exactly how many of the patients had truly oligometastatic disease, or moreso, what their overall disease burden was. There is also no data on toxicity, which is important when combining or sequencing high doses of radiation with systemic therapy. Finally, there is no data on local control or rate of progression, as only survival is documented in the NCDB.

\section{Conclusions}

Despite the mounting evidence regarding the facilitative relationship between RT and IMT, optimal timing of both modalities remains limited to theoretical discussions rather than having an established evidence base. To address this knowledge gap, we performed this analysis of a large, contemporary national database. The results demonstrated that there may be an optimal timeframe between RT and IMT administration (2-3 weeks); supporting theoretical evidence that time may be required for immune recognition following RT-mediated antigen release and prior to immunoproliferation. These results also have implications for randomized trials addressing this issue in metastatic NSCLC (NCT03223155).

\section{Acknowledgements}

There are no acknowledgements. There was no funding for this study. This study has not been presented or published in part or full form elsewhere. All authors declare no conflicts of interest.

\section{References}

1. Siegel RL, Miller KD, Jemal A. Cancer statistics, 2018. CA Cancer J Clin. 2018; 68(1): 7-30.

2. Chute CG, Greenberg ER, Baron J, et al. Presenting conditions of 1539 population-based lung cancer patients by cell type and stage in New Hampshire and Vermont. Cancer. 1985; 56(8): 2107-11.

3. Sholl LM. Biomarkers in lung adenocarcinoma: a decade of progress. Arch Pathol Lab Med. 2015; 139(4): 469-80.

4. Carbone DP, Reck M, Paz-Ares L, et al. First-Line Nivolumab in Stage IV or Recurrent Non-Small-Cell Lung Cancer. N Engl J Med. 2017; 376(25): 2415-26.

5. Gandhi L, Rodriguez-Abreu D, Gadgeel S, et al. Pembrolizumab plus Chemotherapy in Metastatic Non-Small-Cell Lung Cancer. N Engl J Med. 2018; 378(22): 2078-92.

6. Palma DA, Olson RA, Harrow S, et al. Stereotactic Ablative Radiation Therapy for the Comprehensive Treatment of Oligometastatic Tumors 
(SABR-COMET): Results of a Randomized Trial. International Journal of Radiation Oncology • Biology • Physics. 2018;1 02(3): S3-S4.

7. Gomez DR, Blumenschein GR, Jr., Lee JJ, et al. Local consolidative therapy versus maintenance therapy or observation for patients with oligometastatic non-small-cell lung cancer without progression after first-line systemic therapy: a multicentre, randomised, controlled, phase 2 study. Lancet Oncol. 2016; 17(12): 1672-82.

8. Formenti SC, Demaria S. Systemic effects of local radiotherapy. Lancet Oncol. 2009; 10(7): 718-26.

9. Weichselbaum RR, Liang $H$, Deng L, et al. Radiotherapy and immunotherapy: a beneficial liaison? Nat Rev Clin Oncol. 2017; 14(6): 365-79.

10. Barker HE, Paget JT, Khan AA, et al. The tumour microenvironment after radiotherapy: mechanisms of resistance and recurrence. Nat Rev Cancer. 2015; 15(7): 409-25.

11. Antonia SJ, Villegas A, Daniel D, et al. Durvalumab after Chemoradiotherapy in Stage III Non-Small-Cell Lung Cancer. N Engl J Med. 2017; 377(20): 1919-29.

12. Lehrer EJ, Peterson J, Brown PD, et al. Treatment of brain metastases with stereotactic radiosurgery and immune checkpoint inhibitors: An international meta-analysis of individual patient data. Radiother Oncol. 2018.

13. Lu VM, Goyal A, Rovin RA, et al. Concurrent versus non-concurrent immune checkpoint inhibition with stereotactic radiosurgery for metastatic brain disease: a systematic review and meta-analysis. J Neurooncol. 2018.

14. Hasan S, Renz P, Turrisi A, et al. Dose escalation and associated predictors of survival with consolidative thoracic radiotherapy in extensive stage small cell lung cancer (SCLC): A National Cancer Database (NCDB) propensity-matched analysis. Lung Cancer. 2018; 124: $283-90$

15. Hasan S, Renz P, Wegner RE, et al. Microsatellite Instability (MSI) as an Independent Predictor of Pathologic Complete Response (PCR) in Locally Advanced Rectal Cancer: A National Cancer Database (NCDB) Analysis. Ann Surg. 2018.

16. Deyo RA, Cherkin DC, Ciol MA. Adapting a clinical comorbidity index for use with ICD-9-CM administrative databases. J Clin Epidemiol. 1992; 45(6): 613-9.

17. Meier ELKaP. Nonparametric Estimation from Incomplete Observations. Journal of the American Statistical Association. 1958; 53(282): 457-81.

18. Cox DR. Regression Models and Life- Tables. Journal of the Royal Statistical Society. 1972; 34(2): 187-220.

19. D’Agostino RB, Jr. Propensity score methods for bias reduction in the comparison of a treatment to a non-randomized control group. Stat Med. 1998; 17(19): 2265-81.

20. Shaverdian N, Lisberg AE, Bornazyan K, et al. Previous radiotherapy and the clinical activity and toxicity of pembrolizumab in the treatment of non-small-cell lung cancer: a secondary analysis of the KEYNOTE-001 phase 1 trial. Lancet Oncol. 2017; 18(7): 895-903.

21. Horn L, Spigel DR, Vokes EE, et al. Nivolumab Versus Docetaxel in
Previously Treated Patients With Advanced Non-Small-Cell Lung Cancer: Two-Year Outcomes From Two Randomized, Open-Label, Phase III Trials (CheckMate 017 and CheckMate 057). J Clin Oncol. 2017; 35(35): 3924-33.

22. Reck M, Rodriguez-Abreu D, Robinson AG, et al. Pembrolizumab versus Chemotherapy for PD-L1-Positive Non-Small-Cell Lung Cancer. N Engl J Med. 2016; 375(19): 1823-33.

23. Verma V, Cushman TR, Selek U, et al. Safety of Combined Immunotherapy and Thoracic Radiation Therapy: Analysis of 3 Single-Institutional Phase I/II Trials. Int J Radiat Oncol Biol Phys. 2018; 101(5): 1141-8.

24. Verma V, Cushman TR, Tang $C$, et al. Toxicity of radiation and immunotherapy combinations. Adv Radiat Oncol. 2018; 3(4): 506-11.

25. von Reibnitz D, Chaft JE, Wu AJ, et al. Safety of combining thoracic radiation therapy with concurrent versus sequential immune checkpoint inhibition. Adv Radiat Oncol. 2018; 3(3): 391-8.

26. Onishi H, Shirato H, Nagata Y, et al. Hypofractionated stereotactic radiotherapy (HypoFXSRT) for stage I non-small cell lung cancer: updated results of 257 patients in a Japanese multi-institutional study. J Thorac Oncol. 2007; 2(7 Suppl 3): S94-100.

27. Bernstein MB, Krishnan S, Hodge JW, et al. Immunotherapy and stereotactic ablative radiotherapy (ISABR): a curative approach? Nat Rev Clin Oncol. 2016; 13(8): 516-24.

28. Lee Y, Auh SL, Wang Y, et al. Therapeutic effects of ablative radiation on local tumor require CD8+ T cells: changing strategies for cancer treatment. Blood. 2009; 114(3): 589-95.

29. Verma V. Economic sustainability of immune-checkpoint inhibitors: the looming threat. Nat Rev Clin Oncol. 2018; 15(12): 721-2.

30. Verma V, Sprave T, Haque $\mathrm{W}$, et al. A systematic review of the cost and cost-effectiveness studies of immune checkpoint inhibitors. J Immunother Cancer. 2018; 6(1): 128.

31. Hellman S, Weichselbaum RR. Oligometastases. J Clin Oncol. 1995; 13(1): 8-10.

32. Niibe Y, Hayakawa K. Oligometastases and oligo-recurrence: the new era of cancer therapy. Jpn J Clin Oncol. 2010; 40(2): 107-11.

33. Cushman TR, Caetano MS, Welsh JW, et al. Overview of ongoing clinical trials investigating combined radiotherapy and immunotherapy. Immunotherapy. 2018; 10(10): 851-0.

34. Kalbasi A, June $\mathrm{CH}$, Haas N, et al. Radiation and immunotherapy: a synergistic combination. J Clin Invest. 2013; 123(7): 2756-63.

35. Tang $\mathrm{C}$, Wang $\mathrm{X}$, Soh $\mathrm{H}$, et al. Combining radiation and immunotherapy: a new systemic therapy for solid tumors? Cancer Immunol Res. 2014; 2(9): 831-8.

36. Vanpouille-Box C, Alard A, Aryankalayil MJ, et al. DNA exonuclease Trex1 regulates radiotherapy-induced tumour immunogenicity. Nat Commun. 2017; 8: 15618.

37. Gabani P, Fischer-Valuck BW, Johanns TM, et al. Stereotactic radiosurgery and immunotherapy in melanoma brain metastases: Patterns of care and treatment outcomes. Radiother Oncol. 2018; 128(2): 266-73. 